\title{
A APROPRIAÇÃO DA NATUREZA PELO MARKETING IMOBILIÁRIO EM SALVADOR, BAHIA, NO CONTEXTO DE UMA SOCIEDADE DE RISCO AMBIENTAL
}

\section{THE APPROPRIATIONS NATURE BY THE REAL ESTATE MARKETING IN SALVADOR, UNDER THE ENVIRONMENTAL RISK SOCIETYS CONTExt}

\author{
1Juliana Campos De Oliveira \\ ${ }^{2}$ Rafaela Campos De Oliveira
}

\begin{abstract}
RESUMO
O presente artigo pretende abordar a temática que envolve a apropriação da natureza pelo marketing imobiliário, atribuindo enfoque especial à cidade de Salvador, abordando o atual contexto da Sociedade de Risco. Parte-se do pressuposto de que o marketing imobiliário tem auferido proveito das considerações em defesa do meio ambiente natural, vendendo a imagem de preocupação com a preservação ambiental, mas, em verdade, buscando supervalorizar seus imóveis pela apropriação da natureza. Para o satisfatório alcance dos objetivos pretendidos, será realizada pesquisa de fontes bibliográficas, que abordem questões urbanísticas e relativas à sociedade de risco e à atuação do mercado imobiliário nas cidades. Adicionalmente será realizada análise qualitativa de material de propaganda, que retrate a prática de apropriação da natureza pelo marketing imobiliário na cidade de Salvador, Bahia, onde é intensa a atuação do mercado imobiliário, sobretudo no sentido de apropriar-se da riqueza natural presente na cidade.
\end{abstract}

Palavras-chave: Sociedade de risco ambiental, Apropriação da natureza, Marketing imobiliário, Salvador

\begin{abstract}
This article aims to address the issue involving the appropriations nature by the real estate marketing, making a particular focus on the Salvador, under the presente Environmental Risk Societys context. We have been understood that real estate marketing has been earned the benefits of the natural environment defense considerations, selling a environmental preservation image, but, in fact, seeking to overvalue their homes by the natures appropriation. For the satisfactory achievement of the intended objectives, this research will be conducted by literature sources about the urban issues and the Risk Society and the roles housing Market in the cities. In addition it will be carried out qualitative analysis of advertising material that portrays the natures appropriations practice by the real marketing estate in Salvador city, Bahia Estate, where there is a intenseve housing market activity, especially in the sense of the natural wealths appropriation in the city .
\end{abstract}

Keywords: Environmental risk society, Natures appropriation, Real estate marketing, Salvador

\footnotetext{
1 Doutoranda em Arquitetura e Urbanismo pelo Programa de Pós-Graduação em Arquitetura e Urbanismo da Universidade Federal da Bahia. Universidade Federal da Bahia - UFBA São Paulo. Brasil

E-mail: julipbp@yahoo.com.br

2 Doutoranda em Arquitetura e Urbanismo pelo Programa de Pós-Graduação em Arquitetura e Urbanismo da Universidade Federal da Bahia. Universidade Federal da Bahia - UFBA São Paulo. Brasil

E-mail: rafinhabmcampos@yahoo.com.br
} 


\section{Introdução}

A configuração moderna de sociedade de risco ambiental, caracterizada pela escassez de recursos naturais e realidade social caótica, favorece a captura do discurso ambiental pelo mercado capitalista, particularmente, o mercado imobiliário, que o adequa em favor da aquisição de vantagens monetárias.

A natureza adquire, no contexto urbano, alto valor de troca, e constitui fator de valorização de imóveis. Neste sentido, configura realidade constante no cenário das grandes cidades brasileiras, forte tendência a apreensão da natureza pelos empreendimentos imobiliários, tanto daquela realmente existente, quanto da idealizada, falseada.

Para vender imóveis, o marketing imobiliário utiliza artifícios dos mais diversos, em muitos casos, apreendendo a natureza em propagandas que muitas vezes extrapolam o limite do real, na tentativa de iludir os prováveis compradores, com promessas de vida feliz e desvinculada da realidade das grandes cidades, através de suposto convívio com a natureza.

Ao encontro dos fatos, constata-se que tal situação é verificada também em Salvador, capital do Estado da Bahia, metrópole detentora de grande potencial turístico, que se destaca no cenário nacional e mundial, por dispor, entre outros fatores, de diversificada riqueza natural.

Diante dos fatos, o presente artigo pretende tratar da apreensão da natureza pelo marketing imobiliário, atribuindo enfoque especial à cidade de Salvador.

Para tanto, será realizada pesquisa de fontes bibliográficas que abordem questões urbanísticas e relativas à sociedade de risco e à atuação do mercado imobiliário nas cidades. Adicionalmente, será realizada a análise de fotografias; folders, divulgações, por meio da internet, enfim, de fontes que retratem a prática de apropriação da natureza pelo marketing imobiliário na cidade de Salvador.

Pretende-se destacar exemplos de propagandas de imóveis em diversos setores da cidade de Salvador que dispõem da existência de meio ambiente natural. Os exemplos serão referentes às regiões do Itaigara, Pituba, Pituaçu, Federação, Baía de Todos os Santos, Avenida Paralela, Praia do Forte, por se tratarem de setores considerados nobres, onde se verifica intensa atuação do mercado imobiliário.

Adicione-se, não é intensão realizar análise quantitativa, mas abordagem qualitativa de realidade bastante presente no cotidiano das metrópoles brasileiras, a exemplo de Salvador, qual seja, a dominação do mercado imobiliário e a apropriação da natureza por parte deste setor. 


\section{O meio ambiente natural no contexto da sociedade de risco}

Realizando digressão temporal, até o século XV, tem-se que, naquela época, estava ocorrendo substituição do modo de produção feudal pelo modo de produção capitalista, fato que marcou o início da Idade Moderna e representou verdadeira "revolução social”, devido, entre outros fatores, ao crescimento das cidades, desenvolvimento das manufaturas, aumento populacional, desencadeando no progresso do comércio, modificando a estrutura social que existiu durante séculos (MACHADO, p. 1).

Desta forma, admite-se que a modernidade está relacionada com o desenvolvimento do Capitalismo, tendo se consolidado com a Revolução Industrial, gerando, em todo o mundo, aumento na produção de vários tipos de bens e grandes mudanças na vida e no trabalho das pessoas. Passou a haver, além do desenvolvimento industrial, avanços nos setores tecnológico e científico (REBOUÇAS, 2003, p.38).

Assim, devido aos avanços tecnológicos, o ser humano experimentou uma explosão desenvolvimentista jamais ocorrida, o que trouxe condições favoráveis à erradicação de algumas epidemias, a cura de doenças, a descoberta de mecanismos de prolongamento da vida humana, alargando as fronteiras do conhecimento e propiciando também uma explosão demográfica sem parâmetros na sua história (SANTOS, 1996, p. 217).

Mas, por outro lado, gerou alguns prejuízos, sobretudo, se se considerar a degradação ambiental decorrente desse desenvolvimento técnico-científico industrial. A produção de bens em excesso, a cultura consumista e o aumento sem planejamento populacional são fatores que contribuíram para o desencadear de uma crise ambiental (BARBOSA, 2005, p.19).

Considera-se que a crise ambiental consiste em escassez de recursos naturais e em diversas catástrofes em nível planetário, surgidas a partir das ações degradadoras do ser humano na natureza (LEITE E AYALA, 2010, p. 23).

Diante de tais fatos, considera-se que a sociedade configurada após a Revolução Industrial tem como característica ser uma sociedade de risco. Isto porque, o modelo de desenvolvimento econômico e industrial proveniente da Revolução Industrial prometia o bem-estar para todos, mas não cumpriu com o prometido, uma vez que, apesar dos benefícios tecnológicos, trouxe a devastação planetária e indiscriminada (IDEM, p. 24).

Sociedade de risco consiste em modelo sociológico, desenvolvido por Ulrich Beck, que descreve o estado em que se encontra a sociedade pós-moderna: diante da organização capitalista dos processos de exploração dos recursos naturais, em que os perigos e os riscos 
advêm das mais diversas origens, o que dificulta o controle desses problemas por parte dos diversos setores da sociedade, entre os quais, a sociedade civil, as organizações associativas, as instituições públicas ou privadas (LEITE E AYALA, 2002, p. 11).

Menezes considera que o risco é fruto da modernidade, e, como consequência da globalização e do progresso da ciência, que se desenvolveu de diversas maneiras, principalmente sem a necessária sustentabilidade, dando ensejo à crise ambiental (2003, p.

125). De acordo com Castro,

os riscos advindos dessa incontrolável sede do homem de explorar o meio ambiente encontram-se fora da órbita de seu conhecimento, passando, então, a ocupar uma posição de insegurança, de futuro incerto para sociedade contemporânea (2003, p.146).

A sociedade de risco convive com problemas como a poluição atmosférica, do solo, das águas, sonora, visual, os desmatamentos, a diminuição da camada de ozônio, para citar alguns. São notícias de guerra, fome, acidentes nucleares, risco de armas biológicas, a miséria de grande parte da população, a qual tem propiciado insensata exploração das fontes naturais de riqueza. São fatores que afetam a qualidade de vida dos cidadãos e a dignidade e harmonia do meio ambiente (MENEZES, 2003, p.124).

A palavra-chave da sociedade de risco é "insegurança". Hoje, se vive num ambiente inseguro, diante do paradoxo entre a tecnologia e o desequilíbrio, em que se está constantemente à iminência de acontecimentos catastróficos e irreparáveis para a natureza, decorrentes da atividade humana egoística, individualista e utilitarista. Milaré e Coimbra consideram que

assistimos a escalada sem controle dos riscos ambientais globais, para cuja proliferação todos nós temos contribuído em alguma medida.(...)há muito mais antropocêntrico em nossos cotidianos individuais e coletivos do que ecocêntrico. $\mathrm{Na}$ verdade, sentimos que a cosmovisão ecocêntrica é profundamente incômoda, visto que forçaria os indivíduos, as sociedades e os governos a contrariarem seus respectivos interesses, tirando-nos a todos do nosso pseudoconforto para nos preocuparmos com a sobrevivência do planeta. E como operacionalizar uma profunda mudança em nossa civilização?!(...) O ecocêntrico é a antítese perfeita do egocêntrico, seja esse ego um cidadão qualquer, um intelectual, um magistrado, um governante, seja ele um produtor ou consumidor (2004, p. 26).

Diante do problema de risco, o atual modelo de Estado, está pouco apto a lidar com padrões de imprevisibilidade. Menezes (2003, p. 130) salienta que uma tentativa de solução a se buscar é a formação de um Estado do bem-estar ambiental como elemento capaz de administrar os riscos provenientes da sociedade pós-moderna. 
Leite e Ayala (2010, p. 25) asseveram que o Estado de bem-estar marginalizou a questão ambiental devido ao fato de supervalorizar as politicas de pleno emprego e de maximização da utilização dos fatores da produção, ignorando o desenvolvimento de uma politica ambiental que objetivasse a melhor qualidade de vida.

Para construção de um Estado de bem-estar ambiental, os autores admitem que a maior dificuldade é transformá-lo em um Estado de justiça ambiental. Entendem que para se formular uma política ambiental com justiça ambiental, é necessário que o Estado se guie por princípios que vão se formando a partir da sedimentação das complexas questões suscitadas pela crise ambiental (IDEM, p. 47-48).

Aliado a isto, é necessário que haja uma conscientização global da crise ambiental. Esta conscientização exige uma cidadania participativa, que compreende ação conjunta do Estado e da coletividade na proteção ambiental. Não se pode adotar uma visão individualista sobre a proteção ambiental, sem solidariedade e desprovida de responsabilidades difusas globais (IDEM, 2010, p.25).

Adicione-se, a proteção do meio ambiente não pode ser analisada sob um ponto de vista isolado. É necessário que haja a comunhão dos mais diversos ramos do conhecimento científico, tais como, o urbanismo, o direito, a química, a biologia, a geografia, dentre outros (CASTRO, 2003, p. 146).

Em conformidade com Menezes (2003, p. 140), admite-se que não se pode edificar um ambiente saudável sem que haja o entendimento de que ele será para todos em geral e a ninguém em particular. Não se cria um ambiente sadio para determinadas pessoas, mas para toda a coletividade. Necessita-se criar um novo modo vida, de forma a que o homem não venha a destruir a natureza e esta não venha a deixa-lo sem perspectivas de sobrevivência.

Contudo, tais recomendações parecem um tanto distantes da realidade urbana, quando se leva em consideração o descaso por parte dos setores mais influentes da sociedade pelas questões ambientais. As grandes empresas privadas, detentoras do poder econômico, manipulam as decisões do Poder Público a seu favor.

Henrique ressalta que na maioria das cidades constata-se que apenas alguns elementos naturais são valorizados, como a vegetação, que é transformada em área verde. Entretanto, frequentemente são presenciadas obras que aterram ou canalizam córregos e rios (2009, p. 22).

Restringindo-se a atuação do Estado frente ao mercado imobiliário no município de Salvador, por exemplo, tem-se que há a adoção de postura permissiva diante dos movimentos 
especulativos, com a tomada de iniciativas que submetem a organização do espaço urbano aos interesses e demandas do capital imobiliário (CARVALHO E PEREIRA, 2003, p. 103).

À título ilustrativo, cabe destacar ainda dados esboçados por Copque et al (2011) referentes à Avenida Luis Viana Filho, importante eixo viário que faz a ligação de Salvador com o Litoral Norte da Bahia (CARVALHO E PEREIRA, 2008, p. 89). Com base em Mascarenhas, Copque et al (2011, p. 708) revelam que, em 1995, a Prefeitura do Salvador publicou um documento intitulado "Uma Abordagem Ambiental para o Manejo do entorno da Avenida Luiz Viana Filho", com considerações que direcionavam para a expansão da cidade no entorno desta avenida, destacando a necessidade de proteção e controle da Mata Atlântica e cursos d'água que a circundam. Constatou-se, entretanto, que tal situação foi desconsiderada no Plano Diretor de Desenvolvimento Urbano de Salvador (Lei nº7.400/08), onde a Avenida é vista como área de expansão habitacional e de serviços, sem mecanismos de proteção ao ambiente natural.

Diante de realidades como tais, o fio de esperança que resta é a união organizada da sociedade civil que, consciente da sua imensa responsabilidade perante a proteção da natureza, atue contundentemente contra os desmandos da classe capitalista dominante. Esta se configura tarefa difícil, principalmente quando se constata que grande parcela dos cidadãos demonstra descaso perante as questões ambientais, além de nutrir fortes tendências ao individualismo e egoísmo. E conseguir conscientização ambiental desta parcela da população é missão árdua, praticamente impossível. Mas não se pode desistir.

\section{Uso da natureza como instrumento de valorização imobiliária}

Diante da realidade explanada no capítulo anterior, considera-se que a emergência da sociedade de risco supra mencionada, fez que, crescentemente, houvesse a difusão do interesse de parcela da sociedade moradora das grandes cidades, em especial, aquela detentora de alto poder aquisitivo, pelo convívio com a natureza, visto enquanto privilégio, instrumento qualificador da vida urbana.

Neste sentido, tem havido tendência à aceitação de abordagens enaltecedoras da necessidade de interação harmônica do homem com a natureza. Desta forma, concomitantemente aos discursos em defesa da natureza, têm sido constantes deturpações das considerações ambientalistas, traduzidas em exploração do patrimônio natural, pelos diversos setores de mercado, entre os quais, o de cosméticos, o alimentício, o imobiliário 
(HENRIQUE, 2009, p. 102), sob uma pseudo atitude de "preocupação" com a manutenção da diversidade natural.

Considera-se que, apesar dos discursos presentes sobre a 'destruição' da natureza pelos agentes do capitalismo, devido às características de cada momento do modo de produção capitalista, se produza uma natureza particular e de interesse, sob a ótica do capital, daquele conjunto momentâneo das situações. Assim, o capitalismo não destrói a natureza, mas sim a transforma e a produz constantemente, na busca ininterrupta pelo lucro e pela valorização constante das mercadorias e dos objetos (IDEM, p. 104).

Constata-se que o mercado capitalista passou a utilizar a natureza, nas cidades, como objeto rentável, apropriando-se, de forma exploratória, enquanto mercadoria. Castells ao abordar o processo de "mercadorização" da natureza pelo capitalismo ressalta que "basta pensar no processo de privatização dos recursos naturais para observar que nada pode escapar ao grande capital; no interior de uma lógica capitalista dominante, tudo, absolutamente tudo, pode tornarse mercadoria" (1983, p. 491).

Por via de consequência, o mercado imobiliário, em especial, apropria-se da natureza na cidade, como forma valorizar seus empreendimentos. Coaduna-se com o que destaca Henrique: "repete-se uma velha lei do mercado. A escassez de algum produto, no caso, da natureza, faz seu preço aumentar. O mundo capitalista parece ver, (...) a natureza como um posto de combustível para exploração humana” (2009, p. 109).

O marketing imobiliário, em muitos casos, difunde a ideia de que o viver bem na cidade está associado ao convívio próximo à natureza, o que leva ao aumento do valor dos imóveis localizados em setores da cidade onde a riqueza natural é predominante. O objetivo é atrair consumidores de alto poder aquisitivo, dispostos a pagar exorbitantes valores monetários para desfrutar de suposto convívio saudável junto à natureza.

De acordo com Lefebvre, os promotores de venda apresentam projetos com "ocasião e local privilegiados: lugar de felicidade numa vida quotidiana miraculosa e maravilhosamente transformada" (2011, p. 32).

Os clientes/consumidores/adoradores da natureza são dominados e não percebem que esta natureza vendida não passa de uma mentira, um engodo. Estes empreendimentos transformam, desta maneira, a natureza numa 'coisamercadoria' onde estas passam a ter seu valor definido em função das ideologias impregnadas em seu conteúdo e aparência (HENRIQUE, 2009, p. 108).

Tais compradores se dispõem a pagar os altos valores monetários, para usufruir do que Henrique considera uma natureza congelada, carregada de ideologia, transformada em cartão postal, em fetiche (2008, p. 204). Em conformidade com SANTOS (2000, p. 10), pagam 
para ser enganados. Henrique salienta ainda que "esta natureza artificial, produto da ação humana e, de mentira, (...) encontra-se hoje compromissada com uma felicidade capitalista" (2008, p. 204).

A falta de veracidade do uso da natureza pelo marketing imobiliário reside, sobretudo, no fato de que se busca acobertar os males da cidade, ofuscando-se a miséria, a violência, a falta de solidariedade e de cidadania (ROCHA, 2003, p. 66). Transmite-se a ideia de que, morando próximo à natureza, o cidadão livra-se dos tantos problemas inerentes à realidade atual das grandes cidades.

Lefebvre considera que todas as condições se reúnem "para que exista uma dominação perfeita, para uma exploração apurada das pessoas, ao mesmo tempo como produtores, como consumidores de produtos, como consumidores de espaço" (2011, p. 33).

Pretende-se a difusão de um mundo encantado, perfeito, repleto de ilusões, longe do "mal" das cidades. Cria-se uma utopia infantilóide acerca da possibilidade de se viver em lugar de sonhos e plenitude do "bem", a partir da representação glamourizada, reificada e caricaturizada da natureza, que é vista como se numa tela de cinema. A este processo Harvey conceitua como "Disneyficação da Natureza" (2000, p. 219).

Harvey considera que a disneyficação configura a ideia de espaço supostamente feliz, harmonioso e sem conflitos, apartado do mundo real; de entretenimento; de história inventada; de cultivo de nostalgia de um passado mítico; do fetiche pela cultura da mercadoria; da reunião de objetos e coisas difusoras da ideia de diversidade e existência multicultural, mesmo que ocorra na forma de compartimentos; de lugar limpo, higienizado e mitologizado, esteticamente perfeito (IDEM, IBIDEM).

Além disso, na atual conjuntura da sociedade de risco, com degradação crescente dos recursos naturais, viver próximo à natureza parece estar associado a realidade privilegiada. Neste sentido, o mercado imobiliário tem agido de modo a adquirir vantagens, vendendo imóveis a altos valores, devido ao "privilégio" de se localizarem em áreas onde há vasta riqueza natural.

Percebe-se uma notória e desinibida apreensão, pela esfera privada, de um bem de caráter difuso, portanto, pertencente a todos, e insuscetível de divisão (SIRVINSKAS, 2012, p. 136), que deve ser protegido em prol, tanto das presentes, quanto das futuras gerações, garantindo-se uma equidade intergeracional (LEITE E AYALA, 2010, p. 76).

A indevida apropriação da natureza é realizada, sobretudo, porque há, de acordo com Kowarick, certa fragilidade nas organizações populares para interferir nos processos 
decisórios, o que confere grande liberdade de ação aos grupos privados, que se encontram inteiramente voltados para a obtenção de lucros (1979, p. 33).

Para agravar tal situação, presencia-se uma postura permissiva por parte do Poder Público das metrópoles brasileiras, frente aos movimentos especulativos do mercado imobiliário, que submetem a organização do espaço urbano aos interesses e demandas do capital imobiliário (CARVALHO e PEREIRA, 2008, p.103).

Neste sentido, Kowarick destaca que, com a intensificação da industrialização, acumulação e especulação, passou a haver sobreposição dos interesses imobiliários privados, com o direcionamento dos investimentos públicos à dinâmica de valorização-especulação do sistema imobiliário construtor (1979, p. 31-32).

No Brasil, podem ser citados vários exemplos de apropriação da natureza na cidade pelo setor imobiliário, explorada pelo marketing de venda dos imóveis. De forma ilustrativa, cita-se, neste momento, a cidade de São Paulo, por representar a maior metrópole brasileira e, concomitantemente, um dos lugares no país onde a natureza na cidade é mais escassa, havendo uma negação da natureza romântica e verde (HENRIQUE, 2009, p. 141). Em são Paulo, objetos associados à ideia de natureza adquirem alto valor econômico, fator que estimula a atuação do mercado imobiliário, no sentido de "vender" uma natureza que, em verdade não existe, mas que os compradores aceitam acreditar existir.

Após todo o processo de ocupação da cidade, de todo o desenvolvimento técnico da sociedade ocidental, encontrar verde nativo das matas brasileiras num bairro completamente urbanizado de São Paulo (...) não é apenas uma ilusão, como se transforma no mais puro ato enganador que o 'marketing verde' propaga (Henrique, 2009, p. 141).

Exemplo recente de atuação do que Henrique denomina "marketing verde" (IDEM, IBIDEM), em São Paulo é o de um “complexo multiuso", em fase de construção por uma grande empresa imobiliária, cujo slogan do vídeo-divulgação é: "Parque da Cidade: uma cidade dentro de um parque"1. O vídeo mostra pessoas felizes pedalando, fazendo caminhada (destaque para as várias sacolas de compras levadas pelos andarilhos),numa área onde o verde se faz presente, lembrando as características de um Parque, com sobreposições de imagens de um shopping e de um luxuoso restaurante. Nas considerações acerca dos predicados do empreendimento, constata-se forte apelo à sustentabilidade, o que remete ao discutido anteriormente acerca das

\footnotetext{
${ }^{1}$ PARQUE DA CIDADE. Disponível em:〈http://www.youtube.com/>. Acesso em 10 out. 2014.
} 
abordagens pró-natureza, no contexto da sociedade de risco, além da persuasão, através da menção à existência de vínculo a uma empresa internacional:

Conceito amplo de sustentabilidade, nas áreas Ambiental, Social e Econômica. Parque Linear,com $22 \mathrm{mil} \mathrm{m}^{2}$ de área verde, integrando o entorno e permitindo a mobilidade urbana. Complexo em processo de certificação Green Buliding e Triple A. $1^{\circ}$ empreendimento no Brasil certificado do ponto de vista sustentabilidade pela Clinton Foundation, fundação criada pelo Ex. Presidente dos E.U.A. Bill Clinton².

Verifica-se em propagadas deste quilate o que Lefebvre considera uma transcendência à cotidianidade (2011, p.118). O autor revela uma irônica realidade:

Os moradores do Olimpo e a nova aristocracia burguesa(...)não habitam mais. Andam de palácio em palácio, ou de castelo em castelo; comandam uma armada ou um país de dentro de um iate; estão em toda a parte e em parte alguma (IDEM, IBIDEM).

A situação descrita no exemplo supra citado ocorre em diversas outras cidades, do país, onde os interesses do mercado capitalista prevalecem, em detrimento das reais carências inerentes aos centros urbanos nos tempos hodiernos.

Constroem-se e se vendem cidades ilusionarias para compradores que tem poder aquisitivo suficiente para se iludir, para crer ver o invisível que o marketing imobiliário torna visível. Rocha considera que

os marketeiros ocupam papel importante na construção da invisibilidade e visibilidade da cidade, separando os legítimos interesses da população,(...)dos interesses demagógicos que ocultam propositadamente os males da cidade,(...)através da construção da cidade-vitrine, da cidadeespetáculo, da cidade que ofusca a miséria, a violência, a ausência de solidariedade e a cidadania com seus fogos de artifício, suas festas e seus balangandãs. Esta cidade é constantemente construída e destruída nos outdoors, cartões-postais e cadernos de turismo, pela força da mídia na sociedade, requerendo dos construtores da invisibilidade e visibilidade um permanente diálogo na tentativa de se alcançar uma cidade mais justa, democrática e agradável, pelo resgate da cidadania (2003, p. 66-67).

Segundo Lefebvre (2011, p. 27), “as pessoas se representam a si mesmas através daquilo que lhes falta ou que acreditem faltar. Nesta relação, o imaginário tem mais poder”. Para o autor, esta realidade ilusionaria, criada pelo marketing imobiliário, configura o “imaginário do habitat", onde está presente o sonho, a saúde, afastados da cidade "má e malsã” (IDEM, IBIDEM). Não mais se vende uma moradia ou um imóvel, mas o urbanismo,

\footnotetext{
${ }^{2}$ PARQUE DA CIDADE ODEBRECH. Disponível em:<http://hazielcorretoraapartamentos.blogspot.com.br/>. Acesso em 10 out.2014. que passa a ser reconhecido como valor de troca (IDEM, p.32). E tudo isso acontece
} 
(surpreendentemente ou não), conforme afirmado anteriormente, sob os auspícios do Poder Público.

\section{A apropriação da natureza pelo marketing imobiliário em salvador}

À titulo de esclarecimento, convém ressaltar, preliminarmente, que Salvador representa a capital do Estado da Bahia, localizado na Região Nordeste do Brasil. A cidade constitui metrópole nacional e, nas últimas décadas tem incrementado metropolização turística, o que reforça o fato de ser uma região detentora de grande potencial turístico, que se destaca no cenário nacional e mundial por dispor, entre outros fatores de diversificada riqueza natural (SILVA, et al, 2008, p.197).

Devido a estes fatores, na cidade da Salvador, é bastante comum encontrar menções à natureza, realizadas pelo marketing imobiliário, como estratégia para enaltecer a qualidade de localização e, consequentemente, elevar o valor de imóveis construídos próximos a parques, que contemplam natureza preservada, a praias, entre outras riquezas naturais. Realiza-se uma apropriação da apreciação estética da natureza (HENRIQUE, 2009, p. 127).

Esta forma de apropriação é classificada por Reclus (apud HENRIQUE, 2009, p. 126) como apropriação indireta, ou seja, aquela que utiliza a natureza para a venda de mercadorias, produtos e serviços.

Neste momento, pretende-se demonstrar tal realidade através da exposição de alguns exemplos de propagandas de imóveis em diversos setores da cidade de Salvador, que dispõem da existência de meio ambiente natural. Restringir-se-á às regiões do Itaigara, Pituba, Pituaçu, Federação, Baía de Todos os Santos, Avenida Paralela, Praia do Forte, por se tratarem de setores considerados nobres, onde se verifica intensa atuação do mercado de imóveis, sobretudo, através da apreensão da natureza, tanto daquela existente, quanto da forjada pela astúcia do marketing imobiliário.

Buscou-se elencar exemplos de regiões que se distribuem por setores diversos da cidade e da sua região metropolitana, de modo a analisar a forma de apropriação da natureza adotada pelo marketing imobiliário, a depender do setor de localização dos imóveis.

O Itaigara, que se encontra próximo ao Parque da Cidade Joventino Silva, apresenta muitos casos de propagandas de imóveis fazendo referência ao Parque, como fator de privilégio para aqueles que pretendem morar em empreendimentos próximos à sua natureza preservada. As expressões mais utilizadas são: “O Itaigara você conhece. É um dos bairros mais valorizados de Salvador, um dos endereços mais desejados da cidade. Cercado de muito verde e com uma bela vista para o Parque da Cidade"3; "Possui vista permanente para o Parque da Cidade"4. 
O valor destes empreendimentos varia entre cerca de $\mathrm{R} \$ 800.000,00$ e $\mathrm{R} \$ 1.612 .000,00$, havendo a previsão de valores em moedas alienígenas, a descrição das vendas em outros idiomas ${ }^{5}$, o que demonstra, ainda, o interesse pelo consumidor estrangeiro.

Em alguns casos, o site traz a imagem de verdadeiro "paraíso natural”, discrepante da real imagem da localização dos imóveis à venda, conforme demonstra a figura a seguir, que ilustra um site de venda de imóveis da região do Itaigara:

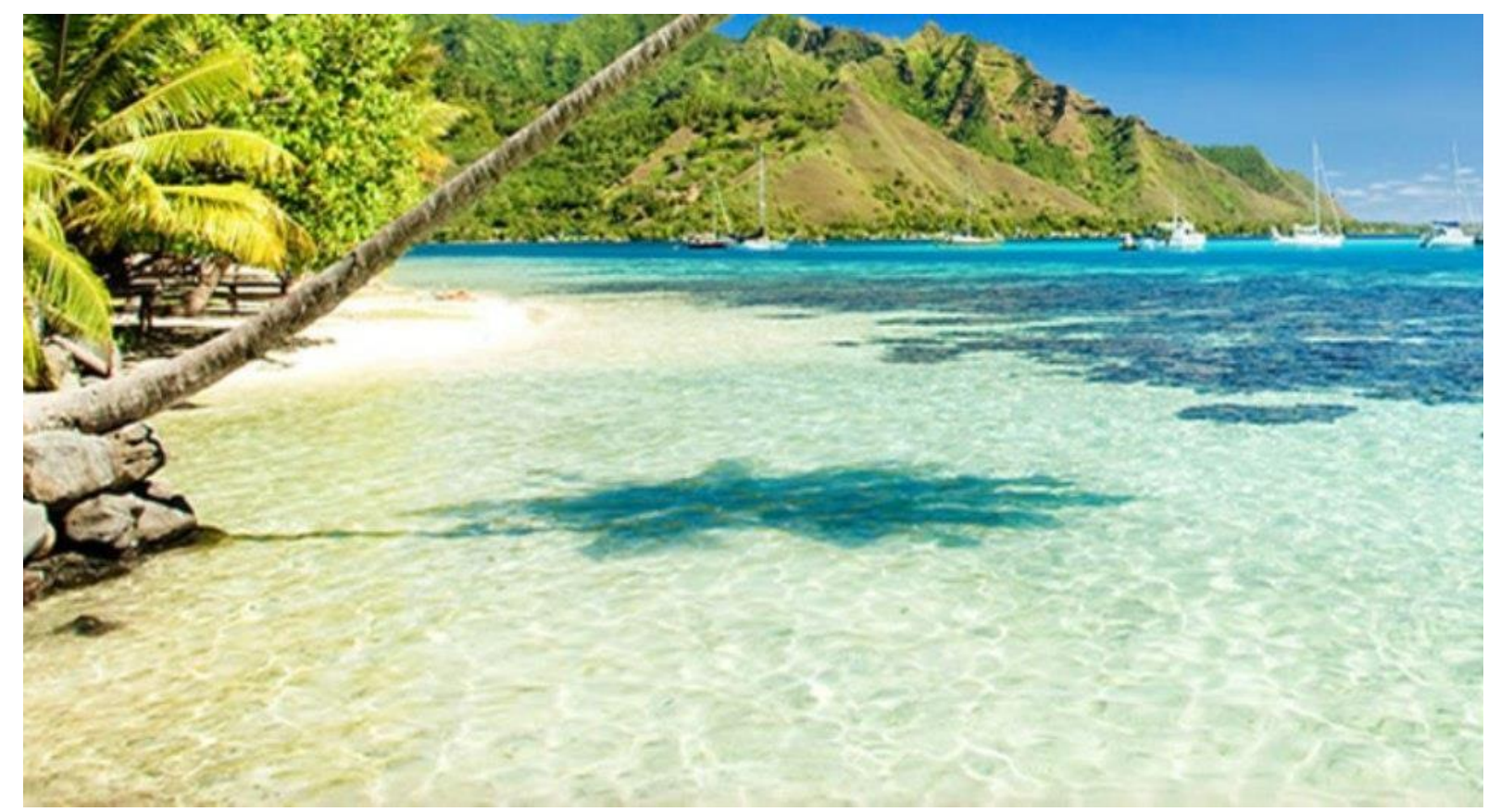

Fonte: TROVIT IMÓVEIS ITAIGARA. Disponível em: <http://imoveis.trovit.com.br>

Em outras situações, são utilizadas fotos ilustrativas da localização do imóvel, com nítidos recursos de tratamento da imagem, que camuflam a realidade do local. Na figura a seguir, transmite-se a ideia de que o imóvel se localiza dentro do Parque da Cidade, por estar rodeado de natureza, não havendo imóveis na região circunvizinha próxima:

\footnotetext{
3 TROVIT IMÓVEIS. Disponível em:<http://imoveis.trovit.com.br/>. Acesso em: 11 out. 2014;

${ }^{4}$ DIAMOND. TROVIT. Disponível em: <http://imoveis.trovit.com.br/>. Acesso em: 12 out. 2014.

5 VIVAREAL. Disponível em:<http://www.vivareal.net/apartment-36968524/>. Acesso em:12out. 2014.
} 


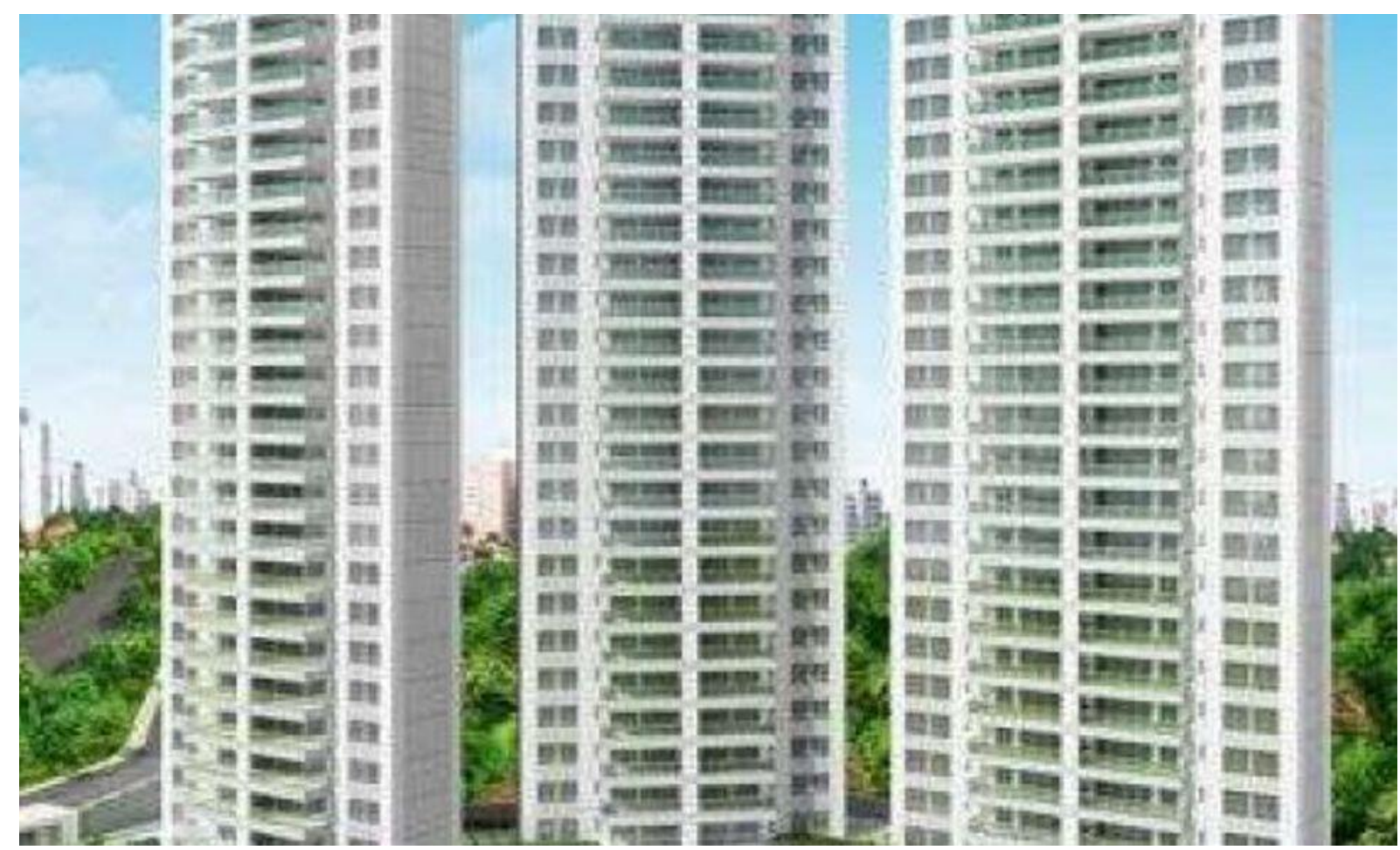

Fonte: DIAMOND.TROVIT. Disponível em: <http://imoveis.trovit.com.br>

No bairro Pituba, vizinho ao Itaigara, contemplado tanto pelo Parque da Cidade quanto pela orla marítima, também são encontrados exemplos de apropriação indireta da natureza. Há um empreendimento que "foi feito para quem tem uma rotina agitada, mas ainda assim sabe aproveitar os prazeres da vida. Um deles é poder chegar em casa e encontrar o mar estendido de uma ponta a outra da sua varanda. Esse privilégio só você tem"6 (grifos nossos). "Afinal nada tem tanta importância quanto viver feliz"7, como se o simples fato de viver de frente para o mar, trouxesse embutida a tão almejada "felicidade"!

Na Federação, outro bairro de Salvador onde são construídos imóveis de luxo, foi trazido o exemplo de um empreendimento que está sendo construído em uma das principais avenidas do bairro, a Cardeal da Silva. No muro do futuro residencial, há um imenso painel, com imagem de natureza, e uma "convidativa" frase:

\footnotetext{
${ }^{6}$ PITUBA PRIVILAGE LOCALIZAÇÃO.Disponível em:<http://www.pitubaprivilege.com.br/>.Acesso em: 15 out. 2014.

${ }^{7}$ PITUBA PRIVILEGE RESIDENCE. Disponível

em: 〈http://www.youtube.com/watch?v=xNMOVm1xKu8>. Acesso em: 15 out. 2014.
} 


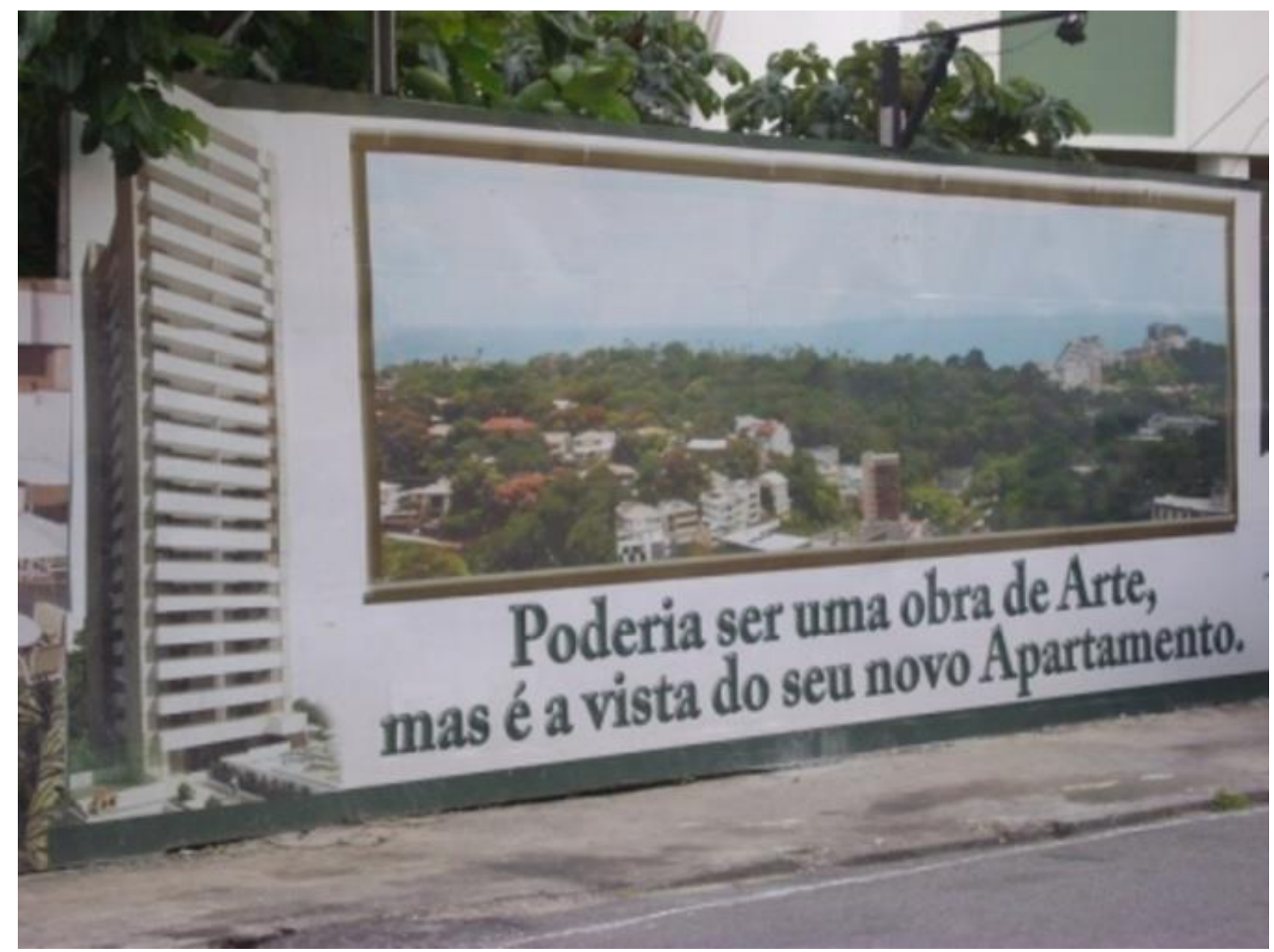

FONTE: Arquivo Pessoal

Neste exemplo, verifica-se certa persuasão da propaganda que impõe, em primeiro lugar, ao público, considerar a imagem, suposta "vista" do empreendimento, bela e agradável e, em segundo lugar, a paisagem enquanto fator suficiente para a escolha do imóvel. Trata-se de propaganda que além de se apropriar da natureza, tem caráter restritivo, uma vez que não considera outras características urbanas do local, como fator de valorização do imóvel.

Anúncio ora interessante, pela audácia, é o de um empreendimento projetado na Baía de Todos os Santos, mais precisamente, na cidade de Salvador, às proximidades do seu centro antigo(Mercado Modelo, Pelourinho).O insidioso anúncio, além de se utilizar da natureza local para o marketing, busca envaidecer os brios do público consumidor comparando-os a Deuses, Reis, a figuras que transmitem ideias de poder e superioridade:

Ir ao mar e entrar em casa, como se fosse Poseidon ou Iemanjá, já não é apenas um sonho possível apenas aos Deuses e entidades que habitam o imaginário humano.Esse sonho já pode ser realizado, somente, em Salvador.Imagine abrir os olhos toda manhã e ter, como diriam alguns baianos, "a dificuldade"de ver a beleza deslumbrante da Baia de Todos os Santos todos os dias.(...)está redefinindo os significados da palavra "lar" na cidade. Agora você poderá dizer: meu lar é no mar e com direito(...)ao mais belo por do sol do Brasil(...)Em um dia de calor(...)você terá a deliciosa 
opção de(...)poder ir, ali, dar um pulinho nas águas da Baia, aproveitando uma das mais belas piscinas naturais do Brasil.(...)Com todos esses privilégios, não se importe em dizer para si, “eu sou o rei do mar"s (grifos do anunciante).

No Pituaçú outro bairro de Salvador onde há, além da orla marítima, o Parque de Pituaçú, também existe exploração da natureza pelo marketing imobiliário. O anúncio:“De um lado a praia. Do outro o Parque. Alto padrão em contato com a natureza"9 (grifos do anúncio), difunde ideia de paz, harmonia, tranquilidade, que, em verdade, são difíceis de ser alcançados com plenitude na atualidade das metrópoles brasileiras.

Ainda em Pituaçú, encontra-se empreendimento imobiliário que se afirma "ecologicamente correto", autodenominando-se "Eco residence"10. Neste caso, constata-se com maior nitidez a influência da atual conjuntura de sociedade de risco sobre os setores do comércio, que cada vez mais pretendem mostrar-se preocupados com a sustentabilidade do planeta.

As margens da Avenida Luís Viana Filho (ou Avenida Paralela), importante eixo viário que faz a ligação de Salvador com o Litoral Norte da Bahia, região onde ocorreu, a partir da segunda metade do século XX, vasta expansão habitacional e de serviços (CARVALHO E PEREIRA, 2008, p. 89), se caracterizam pela presença de Áreas Verdes, a exemplo de resquícios de Mata Atlântica, além de cursos d'água (Copque et al, 2011, p. 708). Este setor é bastante visado pela parcela do mercado imobiliário que, adicionalmente aos imóveis, "vende" a natureza local. Ressalta-se que tal situação se verifica mesmo constatando-se que, em decorrência do crescimento urbano, atualmente permanecem apenas minguados setores onde é possível encontrar natureza conservada (IDEM, p. 712). Os anúncios na região da Paralela vão desde

uma região que vem se firmando, cada vez mais, como o novo pólo urbano da cidade. Próxima das praias e de tudo que a sua família precisa para viver com conforto, a Paralela ainda tem uma outra vantagem: áreas verdes preservadas. (...) Um lugar perto (...) Parque de Pituaçu ${ }^{11}$ (grifos nossos),

\footnotetext{
${ }^{8}$ ADELAIDE: UMA MORADIA DOS DEUSES NA BAÍA DE TODOS OS SANTOS. Disponível em: <http://blogdaponto4.com.br/>. Acesso em: 15 out. 2014.

${ }^{9}$ HEMISPHERE360․ Disponível em: <http://www.hemisphere360.net/>. Acesso em:15 out. 2014.

${ }^{10}$ INFINITY ECO RESIDENCE.OLX. Disponível em:<http://salvador.olx.com.br/105m-infinity-eco-residence- vista-para-o-mar-iid-

393730522>. Acesso em:14out.2014.

${ }^{11}$ TROVIT IMÓVEIS.Disponível

em: <http://imoveis.trovit.com.br/index.php/cod.frame/>.Acesso em:12out.2014.
} 
até: "a posição do terreno e a disposição do empreendimento proporcionam uma bela vista para o mar e um grande contato com a natureza"12 (grifos nossos), como se não houvesse imenso abismo entre morar próximo à natureza e com ela manter contato e isto, diga-se, quando o marketing imobiliário cumpre com a verdade ao afirmar ser o imóvel localizado próximo a áreas verdes. Nesta região, interessantes são as denominações atribuídas aos condomínios: "Brisas"13; "Alphaville"14, "Greenville"15, "Le Parc"16", entre outros. São nomes de fenômenos naturais e/ou elementos da natureza e/ou denominações remetentes a uma realidade campestre, indutores da crença de que tais caracteres podem ser encontrados nesta localidade.

Estendendo-se para a região metropolitana de Salvador, mais precisamente à Praia do Forte, localizada no Litoral Norte da Bahia (ALBAN, 2006, p. 4) muitos são os empreendimentos que fazem proveito das belezas naturais locais. Tanto, que o próximo exemplo trazido afirma ser o "último condomínio fechado de terrenos à beira mar na Praia do Forte"17, tendo como slogan: "chegou sua hora de morar no paraíso"18. E ainda:

\begin{abstract}
Imagine-se entre um mar e uma lagoa inacreditavelmente lindos. Tão lindos que você não vai mais querer sair de lá. Agora, imagine outra situação: você não precisa ir embora desse lugar! Sim, essas duas possibilidade existem e você pode ser um dos poucos privilegiados que poderão dizer que mora, se não no Paraíso, em um lugar muito próximo ao nirvana, (...) é um daqueles empreendimentos que podemos chamar de magníficos. (...) está margeado por belas praias com coqueiros e cercadas por infinitas piscinas naturais de água cristalina ${ }^{19}$ (grifos nossos).
\end{abstract}

Outra propaganda imobiliária na região é mais concisa e direta, porém, não menos pretenciosa: elenca fotos dos espaços naturais da região da Praia do forte, com o "simples" acréscimo de duas frases, no mínimo, capciosas:

\footnotetext{
${ }^{12}$ TROVIT IMÓVEIS.Disponível

em:<http://imoveis.trovit.com.br/>.Acesso em:12out.2014.

${ }^{13}$ BRISAS.TROVIT.Disponível em:<http://imoveis.trovit.com.br/>.Acesso em:11out.2014.

${ }^{14}$ ALPHAVILLE.SALVADOR.Disponível em:<http://alphavillesalvador1.com.br/>.Acesso em:11out.2014.

${ }^{15}$ GREENVILLE.Disponível em:<http://www.greenvillesalvador.com/>.Acesso em:11 out.2014.

${ }^{16}$ LE PARC.Disponível em:<http://www.leparcpronto.com.br/>.Acesso em:11 out.2014.

${ }^{17}$ CONDOMÍNIO PISCINAS NATURAIS.Disponível em:<http://blogdaponto4.com.br/imoveis-novos/piscinas- naturais-em-praia-do-fortechegou-sua-hora-de-morar-no-paraiso/>.Acesso em:15out.2014.

18 IDEM

${ }^{19} \mathrm{IDEM}$
} 


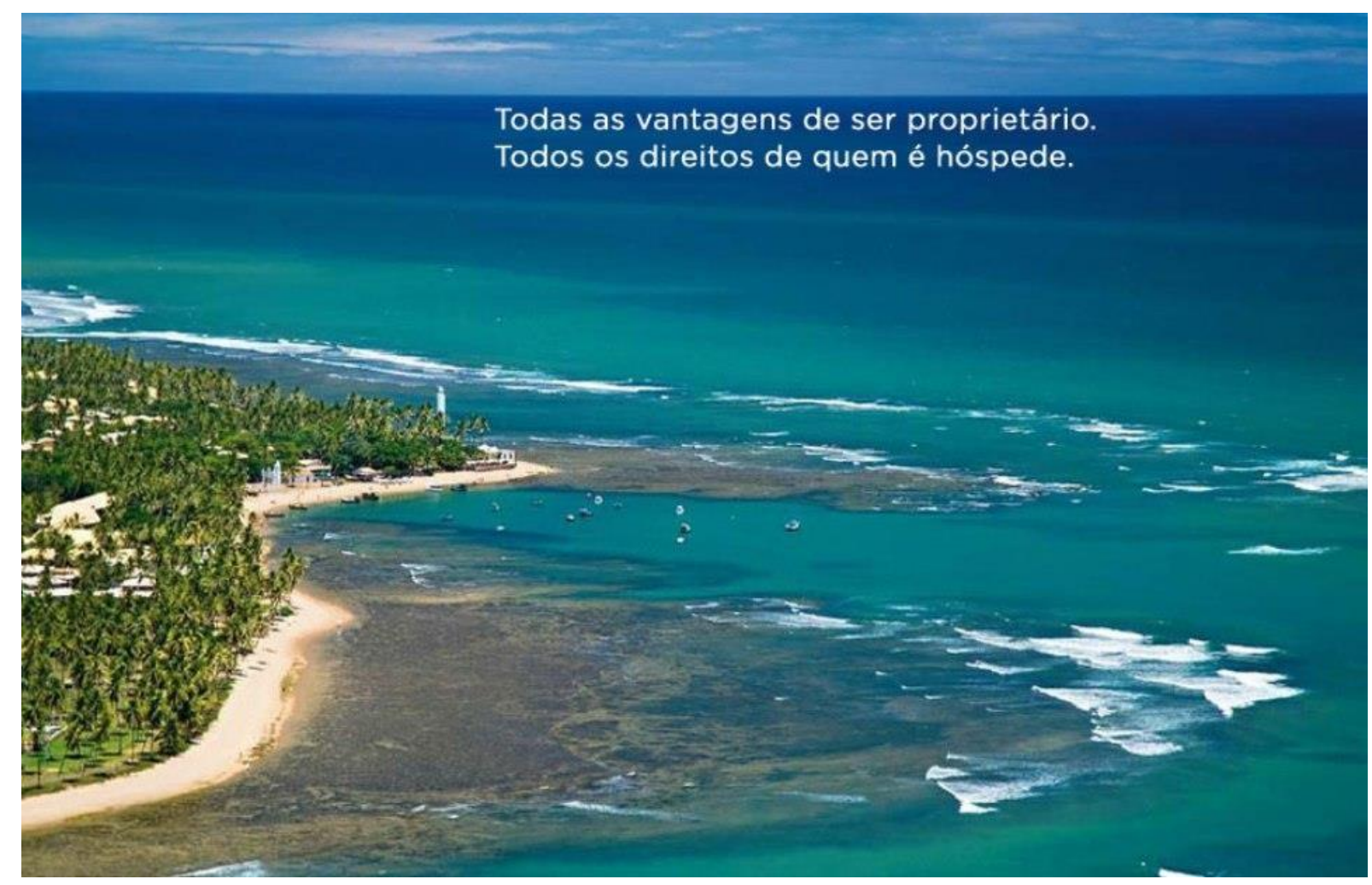

Fonte: TRIVOLI ECORESIDENCES.Disponível em: 〈http://www.tivoliecoresidencespraiadoforte.com/>

Silva et al (2008, p.196), consideram que na região da Praia do Forte está sendo produzido um território de enclaves, ou de guetos (MARCUSE, 2004, p. 24-25) de luxo, "devoradores" de paisagens naturais e culturais.

Constata-se a existência de aparente pressão psicológica imposta pelo marketing imobiliário, que incute nos cidadãos a ideia de um compromisso com a felicidade, ou melhor, com uma suposta felicidade, que estaria presente em imóveis "privilegiadamente" localizados junto a "paraísos naturais". Geram certa ilusão de existência de felicidade, só e somente só, quando se compra (destaque-se: quando se "compra" mesmo quando não se "mora", considerando-se que grande parte dos imóveis são adquiridos por compradores nacionais e estrangeiros que os utilizam apenas em curtos períodos, para férias, por exemplo, como segunda residência (SILVA et al, 2008, p. 194)) um imóvel que esteja localizado próximo à natureza, como se a felicidade não fosse, em verdade, um sentimento abstrato e subjetivo que, de tão complexa definição e entendimento não pode ser simplificada numa sentença rasa: imóvel+natureza+compra=FELICIDADE, ou em outras palavras: imóvel+suposta natureza (promessa de natureza)+compra=RESOLUÇÃO DE TODOS OS PROBLEMAS. 
Neste sentido, Lefebvre ironiza: "eis o contexto, o palco, o dispositivo de sua felicidade. Se você não souber aproveitar a ocasião de pegar a felicidade que lhe é oferecida para fazer dela a sua felicidade é que... inútil insistir!" (2011, p. 32).

Ocorre o que Löwy (2004, p. 373) denomina "ditadura cultural", exercida pelo fetichismo da mercadoria, que é idolatrada como divindade de uma "pseudo-religião. Esta ditatura visa e, pode-se dizer, conquista a redução das relações humanas, dos sentimentos humanos e da produção simbólica.

Adicione-se, a oferta de "luxo", "natureza" e, consequentemente, "felicidade", no contexto da presente discussão, direciona-se apenas à "nobreza" da sociedade. Verifica-se, a preponderância da anteposição e sobreposição dos interesses da parcela populacional mais abastada economicamente, em relação às camadas sociais de menor poder aquisitivo. Harvey esclarece que o uso do solo urbano é determinado por processos de competição (1980, p.115). Neste sentido, ressalta que "o grupo rico pode sempre forçar preferências sobre o grupo pobre, porque ele tem mais recursos para aplicar, tanto para custos de transporte como para obter solo, qualquer que seja a localização que escolha" (IDEM, p. 116).

Entretanto, não se pode esquecer que a natureza é um bem difuso, pertencente a todos, em caráter intergeracional. É completamente equivocado, esdrúxulo, pretender disponibilizar acesso à natureza apenas a reduzida parcela de pessoas que possuem a vantagem de dispor de maior poder aquisitivo.

\section{Considerações finais}

Diante do exposto, considera-se que o marketing imobiliário tem realizado apreensão da natureza nas cidades, em especial, em Salvador, sob a influência, entre outros fatores, do presente contexto de sociedade de risco.

Isto porque, a escassez de recursos naturais, somada à baixa qualidade de vida nas cidades, tem estimulado o marketing imobiliário vender idealizações de "paraísos" na Terra capazes de "curar" as mazelas urbanas.

Agindo de tal forma, apropria-se da natureza, bem de caráter difuso e intergeracional, condicionando bem-estar e felicidade à realidade reducionista e dispendiosa, consistente em morar junto à natureza como luxo e privilégio de poucos.

A apropriação da natureza pelo mercado imobiliário é frequente em todo o Brasil, e necessita ser repreendida, cessada. Os Poderes Públicos não devem permitir que empresas privadas apropriem-se da natureza e a disponibilizem a poucos, impunemente. 
Entretanto, o que se constata, na prática, é uma postura conivente da Administração Pública, que tem, comumente, se mostrado conivente com as práticas do mercado imobiliário, sobretudo, no município de Salvador.

Faz-se mister que a sociedade civil manifeste desaprovação a esta tendência crescente no cenário urbano nacional, demonstrando estar indisposta a aceitar o seu prosseguimento e agindo no sentido de impedir tamanha permissividade, sobretudo através de cobrança de atitude mais enérgica por parte dos Poderes Públicos. Isto porque a natureza pertence a todos, sendo impossível que esteja disponível a servir os caprichos do mercado capitalista.

\section{Referências}

ALBAN, Marcus. 2006 A insustentabilidade do turismo no Brasil e o sucesso de praia do forte: uma análise exploratória com base na nova economia institucional. Seminário Internacional de la Red Iberoamericana de Investigadores em Globalización e Território [Em linha], Bahia Blanca, Argentina. Disponível em: http://www.obsturpr.ufpr.br/artigos/turismo20.pdf [Consult.15set.2012].

BARBOSA, Erivaldo Moreira.2005. Direito Ambiental: em busca da sustentabilidade. São Paulo: Scortecci.

CARVALHO, Inaiá Maria Moreira de; PEREIRA,Gilberto Corso. 2008. As "cidades" de Salvador. In:CARVALHO, Inaiá Maria Moreira de; PEREIRA Gilberto Corso (orgs.). Como anda Salvador e sua região metropolitana. Salvador: Edufba, p81-107.

CASTELLS, Manuel.1983. A questão urbana. Tradução: Arlene Caetano. Rio de Janeiro: Paz e Terra.

CASTRO, Raquel Araújo. 2003.A hermenêutica constitucional americana na sociedade pósmoderna: uma contribuição para a defesa do meio ambiente. Revista de Direito Ambiental, 32 , p.145-158.

COPQUE, Augusto César da Silva Machado; SOUZA, Fabíola Andrade; SANTOS, Denise Vaz de Carvalho; PAIXÃO, Rosevânia Cerqueira da.2011. Expansão urbana e redução de áreas verdes na localidade do Cabula VI: região do miolo da cidade do Salvador, Bahia. Anais XV Simpósio Brasileiro de Sensoriamento Remoto [Em linha], Curitiba. Disponível em: http://www.dsr.inpe.br/sbsr2011/files/p0313.pdf [Consult.10jun.2012].

HARVEY, David.1980. A justiça social e a cidade. São Paulo: Hucitec.

HARVEY, David. 2000. Espaços de esperança. São Paulo: Loyola.

HENRIQUE, Wendel. 2009. O Direito à Natureza na Cidade. Salvador: Edufba. 
2008. Representações da natureza na cidade. In: Angelo Serpa (org.). Espaços Culturais: vivências, imaginações e representações. Salvador: Edufba, p. 201-223.

KOWARICK, Lúcio. 1979. Espoliação Urbana. Rio de Janeiro: Paz e Terra.

LEFEBVRE, Henri. 2011. O Direito à Cidade. Tradução: Rubens Eduardo Frias. 5. ed. São Paulo: Centauro.

LEITE, José Rubens Morato; AYALA, Patryck de Araújo. 2010. Dano Ambiental: do individual ao extrapatrimonial. 3.ed. São Paulo: Revista dos Tribunais.

Universitária.

2002. Direito Ambiental na Sociedade de Risco. Rio de Janeiro: Forense

MACHADO, Fernanda. Feudalismo: servidão, impostos, taxas, suserania e vassalagem. Uol Educação [Em linha].Disponível em: http://educação.uol.com.br/historia/feudalismoservidao-impostos-taxas-suserania-e-vassalagem.jhtm [Consult.20nov.2010].

MARCUSE, Peter.2004.Enclaves, sim; Guetos, não: a segregação e o Estado. Espaço e Debates, 45, p. 24-33.

MENEZES, Paulo Roberto Brasil Teles de.2003.O direito do ambiente na era de risco: perspectivas de mudança sob a ótica emancipatória. Revista de Direito Ambiental, 32, p.123-144.

MILARÉ, Édis; COIMBRA, José de Ávila Aguiar. 2004. Antropocentrismo x ecocentrismo na ciência jurídica. Revista de Direito Ambiental,36,p. 9-41.

REBOUÇAS, Aldo da Cunha.2003.Proteção dos recursos hídricos. Revista de Direito Ambiental, 32, p.33-67.

ROCHA, Luiz Carlos. 2003. Políticas públicas de lazer no subúrbio ferroviário: (in)visibilidade na dinâmica da cidade de Salvador. Dissertação (Mestrado em Educação) Programa de Pós-graduação em Educação e Contemporaneidade, UNEB [Em linha], Salvador, Disponível em:

http://www.ppgeduc.com/dissertacoes/turma_1/2001_13_luiz_carlos_rocha.pdf

[Consult.14set.2012].

SANTOS, Antônio Silveira Ribeiro dos.1996.O Direito Ambiental e a Participação da Sociedade. Revista de Direito Ambiental, 3, p.217-223.

SANTOS, Milton. 2000. Território e sociedade. Entrevista com Milton Santos. 2.ed. São Paulo: Fundação Perseu Abramo.

SILVA, Sylvio Bandeira de Mello; SILVA, Barbara-Christine Nentwig; CARVALHO, Silvana Sá de Carvalho. 2008. Metropilização e turismo no litoral norte de Salvador: de um deserto a um território de enclaves?. In: CARVALHO, Inaiá Maria Moreira de; PEREIRA, Gilberto Corso (orgs.). Como anda Salvador e sua região metropolitana. Salvador: Edufba, p.189-211.

SIRVINSKAS, Luís Paulo.2012. Manual de Direito Ambiental. 10.ed. São Paulo: Saraiva. 
